\title{
WALKING THE ROADS TO REFERENCE SOME COMMENTS ON MARIO GÓMEZ TORRENTE
}

\author{
ELEONORA ORLANDO \\ https:/ / orcid.org/0000-0002-0153-6558 \\ IIF-SADAF-CONICET / University of Buenos Aires \\ Buenos Aires \\ Argentina \\ eleo.orlando@gmail.com
}

\begin{abstract}
Article info
CDD: 401

Keywords

Reference fixing

Reference transmission

Ceteris paribus clauses

Semantic knowledge

Descriptivism vs. Anti-descriptivism
\end{abstract}

Received: 14.09.2020; Revised:24.09.2020; Accepted: 28.09.2020

https://doi.org/10.1590/0100-6045.2020.V43N4.EO

\begin{abstract}
In chapter 3 of the very welcome and enjoyable Roads to Reference, "Proper Names and Referential Indeterminacy", Mario Gómez Torrente proposes a set of conventions establishing merely sufficient conditions for the fixation and transmission of the reference of proper names. There are some aspects of the undoubtedly very original and rigorous proposal that have prompted me the brief comments that follow, grouped into three sections.
\end{abstract}

Gómez Torrente opposes his proposal to an account based on necessary and sufficient conditions, such as the ones advanced by Devitt (2015) and Dickie (2011). He considers those accounts to be either too demanding or too 
loose, and, basically, to give the wrong results in so-called cases of indeterminacy. My point is that the generalizations put forward by those theories could be interpreted along the lines of ceteris paribus laws. According to the Normal Conditions Approach to such laws, a ceteris paribus law holds when normal conditions obtain, namely, only if the situation, without disturbing factors, is a normal or a rather probable situation (Spohn 2002). The general idea behind this approach is that "Ceteris paribus, all As are Bs" means that normally As are Bs. Following this idea, one can think that the conventions establishing necessary and sufficient conditions for reference apply only in normal situations. Without intending to go deep into the different conceptions of normality ${ }^{1}$, I want to suggest that what Gómez Torrente presents as cases of indeterminacy can be considered to be abnormal cases, and as such they are not governed (and should not be expected to be governed) by the conventions contained in the generalizations. In other words, in as far as abnormal cases involve peculiar situations, excluded by ceteris paribus clauses, they must be accounted for independently of the conventions stating necessary and sufficient conditions for reference, presumably in accordance with other principles and commitments of the overarching theory that one defends. Gómez Torrente (2019) claims that "such theories [those stating necessary and sufficient conditions] will not provide an account of the difference between cases where reference fails determinately, as a matter of what referencefixing conventions determinately imply, and cases where no reference is determined, but merely because reference-fixing conventions fail to produce any relevant implication at all" (page 18). My present point is that the former cases are the only ones meant to be covered by the theories at stake, whereas the latter are

${ }^{1}$ The normality condition can be explained in different terms, such as high probability or degrees of belief.

Manuscrito - Rev. Int. Fil. Campinas, v. 43, n. 4, pp. 22-34, Oct.-Dec. 2020. 
abnormal cases, regarding which a decision must be taken on grounds of the adoption of some independent theoretical commitments. So, it is not clear to me why his proposal, positing merely sufficient conditions, should be preferred to an account in terms of both necessary and sufficient conditions with ceteris paribus clauses. In fact, Gómez Torrente claims that he means his account to encompass that kind of clauses:

It is also important to note, as in the case of demonstratives, that the conventions we are about to state must be understood as only roughly sufficient, as they involve conditions that are only sufficient ceteris paribus, in an appropriate sense. That they are ceteris paribus means in this case that the conditions are conventionally taken as sufficient merely under the assumption that the situation where the conditions apply is otherwise normal, that is, not unlike other situations when the conditions were accepted as applying in the past. (page 23)

Well, the same claim can be made concerning both necessary and sufficient conditions: the corresponding conventions are taken to apply ceteris paribus, namely, if the situation involved is otherwise normal.

On any causal account derived from Kripke (1980)'s seminal suggestions, reference borrowing plays a crucial role, since it is the mechanism by virtue of which the communication chain (be it a designational or a denotational one in Devitt (2015)'s terms) is constituted. As is known, a basic condition on reference borrowing is that the name should be used with the same referential intention of the person from whom it is borrowed (as attested by Gómez Torrente's own proposal of Successful name transmission). Now, with this in mind, the example of George Smith can be 
clearly classified as an abnormal case, since the teacher does not have the intention to use the name to refer to his neighbor, as it would happen to any normal case of insertion, by reference borrowing, in a communication chain leading to the neighbor; the case can be assimilated to the use of a random or invented name. ${ }^{2}$

The examples involving conflicting referential intentions, such as the use of 'Madagascar' by Marco Polo, the Barnes example, the Carny example and the Tim example, allow for a similar analysis: given that the corresponding situation is abnormal, the conventions stating necessary and sufficient conditions for reference do not apply, and the explanation of what is going on has to be more cumbersome and may be open for discussion, since it involves taking a stance regarding either some meta-semantic aspects (such as the definition of the concept of grounding) or some independent ontological and epistemological commitments (such as a particular way of carving up reality, or the inclusion of clairvoyance as a form of perceptual knowledge).

For instance, to take Devitt \& Sterelny (1987)'s point of view, 'Madagascar' in Marco Polo's mouth is taken to refer to an island by virtue of a multiple grounding process that takes on board his innovative uses - but this may allow for

2 What about those cases in which, for instance, a person successfully refers to Aristotle by taking part in a communication chain including some uses of the name that are not grounded in the philosopher, namely, uses that seem not to meet the necessary and sufficient conditions for the transmission of reference stated by the theory? I think that those are typical cases of mistakes: when someone sees Plato at a distance and then produces a token of 'Aristotle', I would say it is an abnormal use, grounded in Plato by an understandably mistaken perceptual belief, but without consequences for the semantic convention grounding 'Aristotle' in Aristotle. 
some uses of 'Madagascar' to be indeterminate, let's say, when the situation is not the normal one because the name has not still acquired its referent. ${ }^{3}$ The same holds of the Barnes example: it is a very strange situation in which Barnes's token of 'Nora' seems to involve a baptism, not an insertion in an already existing communication chain - the new name is grounded in an hallucinatory image, so, it would be at most a case of the introduction of a name without a referent. In the Tim example, the speaker is in the grip of another kind of mistake, which causes his introduction of 'Tim' to be grounded in two different trees, unbeknownst to him. Did he fail to refer or did he succeed in referring to some object? The answer may depend on our ontological commitment; for instance, one may think that he succeeded in referring to a tree-fusion constituted by the combination of his two perceptual states.

The example of the clairvoyant who baptizes a dog she cannot perceive through the external senses is also outside normality, since clairvoyance is not a generally acknowledged source of knowledge: necessary and sufficient conditions, defined for normal situations, do not straightforwardly apply. It all depends on whether one agrees that some names can be grounded in objects by means of extra-sensorial perception or not, which is something clearly debatable. Why should one think that necessary and sufficient conditions established for standard cases of perception and description apply to this kind of cases?

In sum, my point is that the generalizations of any standard theory about the fixation and transmission of reference have to be interpreted ceteris paribus, namely, they cannot be supposed to encompass abnormal cases where the decision whether someone succeeds in referring to an object

\footnotetext{
${ }^{3}$ See in particular page 63 of Devitt \& Sterelny (1987), where they put forward the notion of partial reference.
} 
or not will depend on some semantic-independent theoretical commitments. In other terms, they specify conditions of successful reference fixation and transmission for normal cases. Moreover, I do not think that those abnormal cases are intrinsically indeterminate: they are complicated, but it may be possible to elicit a determinate answer if more theory, mostly extra-semantic theory, is brought to the fore - of course, the acceptability of the answer will depend on the scientific credentials of the theory at stake: for instance, if it legitimizes clairvoyance or extrasensorial perception, the provided answer may be found unacceptable.

According to Gómez Torrente's proposal, a speaker must know the reference fixing and transmitting conventions to be competent with proper names; the knowledge in question need not be full knowledge, though, which means that the competent speaker must be somehow familiar with them. In his own words:

[...] being linguistic conventions that are relied upon by the linguistic community at large, the conventions we are after must plausibly be in some sense familiar to normal competent speakers, as we have conceded to the descriptivist. However, unlike the descriptivist, we don't require full knowability of the conventions as such, but merely that the ability to observe them should be manifested in the linguistic behavior of speakers, and specifically in behavior that it should not be unreasonable to think of as behavior that normal speakers do perform. The relevant 
kind of behavior may simply involve the acceptance or denial that particular objects are being talked about with specific uses of names. (pages 21-22, my emphasis)

Gómez Torrente considers his position to be a minor concession to the descriptivist, namely, a concession that does not turn the account into a descriptivist one. My current point is that the intermediate position that he wants to defend is not a stable one. Since Gómez. Torrente is not very specific about the kind of knowledge involved (what he means exactly by not being "knowledge in the full sense"), it is not clear to me, first of all, if he takes it to be practical or propositional, and second, whether he regards it as properly semantic or not.

Is the knowledge of the relevant conventions that he takes to be constitutive of a speaker's competence with names just a kind of practical knowledge, namely, something that is part of her practice or ability to use names competently, or is it a piece of propositional knowledge backing up that practice or ability? Our author claims that "the typical competent speaker can only be expected to recognize particular instances of application of the conventions" (page 22), but, again, it is not clear to me what kind of epistemic capacity is involved in that expectation. Moreover, if it were propositional knowledge, would it be knowledge of general conventions regarding names as a kind of expression, or knowledge of a specific convention concerning each particular name? In the former case, I think the thesis could be accepted by any anti-descriptivist, or Millian, theorist: nobody would deny that being a member of a linguistic community involves being able to perform naming and predicative practices as much as being able to tell them apart from each other. But an anti-descriptivist would reject the claim that being competent with a name consists in having propositional knowledge about the specific conditions, whatever they are, under which it applies to an 
object. Moreover, an anti-descriptivist may agree that a competent speaker usually has some information about the conventions for using names, either general or specific, while rejecting that it is information constitutive of her specifically semantic competence.

In fact, concerning the last point, Gómez Torrente claims that the knowledge at stake is "semantic in a broad sense":

I myself suspect that there are two notions of semantic competence underlying this discussion, closely related to the two senses of "meaning" that (following Kaplan) we distinguished in chapters 1 and 2: a restrictive notion of semantic competence, which involves knowledge of facts about semantic content in the sense of information semantically expressed by expressions or expression-uses, possibly understood as truth-conditional content; and a more encompassing notion of semantic competence about both aspects of semantic content and about "foundational" aspects, which involves knowledge of more facts concerning linguistic conventions bearing on semantic content, though still facts whose knowledge is required of the normal speaker for her to count as competent in a sufficiently broad intuitive sense. (page 9)

But I find this terminology confusing: a descriptivist would consider the knowledge of the naming convention associated with a name plainly semantic, without any need to introduce a broader notion of semantic competence, whereas an antidescriptivist or Millian would take that knowledge to be clearly non-semantic (be it pre-semantic, syntactic, pragmatic, common-sense, or any other non-semantic option she may come up with). 
From my perspective, and setting aside the dispute between descriptivists and anti-descriptivists, it is important to be clear on the specific kind of knowledge, if any at all, that is in play. As is known, a competent speaker can be ascribed different kinds of linguistic abilities (syntactic, semantic, pragmatic), which may be exercised almost simultaneously but are clearly distinct. Suppose that someone claims that the ability to derive a conversational implicature, being tightly associated with the ability to understand the literal meaning of an expression, is semantic "in a broad sense", or that the information conveyed by a conversational implicature is part of the meaning of the expression "in a broad sense". Be that as it may, in the strict sense of these words, that is not the case: the ability and the information at stake are both pragmatic. Likewise, I think it is important to be clear on whether the information about the conventions for introducing and transmitting a name, which can be tightly associated with its competent use, is semantic or not in the strict sense of the word.

Moreover, it should be noticed that bringing the case of demonstratives to the fore does not help in clarifying the point, since in the case of demonstratives there is no dispute concerning the semantic role of the corresponding conventions: in Kaplanian terms, there is no doubt that demonstratives have characters, but... what about names?4 There is no explicit argument in Gómez Torrente's chapter to the effect that the relevant conventions associated with names should be construed as their respective characters.

\footnotetext{
${ }^{4}$ See, for instance, Kaplan's own doubts concerning this possibility in footnote 71 of Kaplan (1989).
} 
The last point I would like to make is more a question than a criticism, and it points to a specific topic, the analysis of fictional discourse, that Gómez Torrente has not explicitly included in the book, so that I would like to now how he might want to expand his proposal so as to address it. As it stands, the proposed conventions do not seem to straightforwardly account for the introduction and transmission of fictional names.

On the one hand, the introduction of fictional names cannot be governed, for obvious reasons, by Successful explicit/implicit name introduction via perceptual intention, since fictional entities, if there were such things, could not be perceived. Moreover, what is more important, Successful explicit/ implicit name introduction via description, replicated below for the sake of clarity, could apply only on the assumption that fictional names refer to fictional entities of some kind -non-existent, merely possible or abstract ones_-, in which they would be grounded by means of using descriptions that they uniquely satisfy:

Successful explicit/implicit name introduction via description: If a speaker $\mathrm{S}$ forms the explicit/implicit intention of using a name $\mathrm{N}$ that she introduces to refer to the object, if any, that uniquely satisfies a certain property $\mathrm{F}$, and it turns out that there is such a unique satisfier of $\mathrm{F}$, then $\mathrm{N}$ as used by $\mathrm{S}$ will refer to the $\mathrm{F}$, if $\mathrm{S}$ forms no intention conflicting with that intention and if $\mathrm{S}$ does not form intentions about how to use $\mathrm{N}$ that on the 
whole conflict with the intentions of the community of users of $\mathrm{N}$ at large. ${ }^{5}$

That would involve giving fictional names a treatment similar to the analysis of Arabic numerals developed in chapter 4. But it would be a complicated path to take, since it encompasses a substantive ontological commitment.

On the other hand, Successful name adoption via description, as in the quote below,

Successful name adoption via description: if a speaker $\mathrm{S}$ forms the (explicit or implicit) intention of using a name $\mathrm{N}$ that she has inherited to refer to the object, if any, that uniquely satisfies a certain property $\mathrm{F}$, and it turns out that there is such a unique satisfier of $\mathrm{F}$, then $\mathrm{N}$ as used by $\mathrm{S}$ will refer to the $\mathrm{F}$, if $\mathrm{S}$ forms no intention conflicting with that intention, and if $\mathrm{S}$ does not form intentions about how to use $\mathrm{N}$ that on the whole conflict with the intentions of the community of users of $\mathrm{N}$ at large. (page 26)

could account for the transmission of fictional names, on the same previously mentioned assumption concerning the metaphysical status of fictional entities. But, again, Gómez Torrente may not want to be ontologically committed to the existence of fictional entities of any kind, in which a different convention should be put forward. Therefore, I would like to finish these brief remarks with a question: what kind of account of fictional discourse would Gómez Torrente be

${ }^{5}$ I have put together the two different conventions given for explicit and implicit introductions, specified in pages 23 and 24 of the book. 
willing to endorse, or would he take to fit better with his theory of reference for standard names?

\section{ACKNOWLEDGEMENTS}

I thank Mario Gómez Torrente for his very interesting book, Marco Ruffino for inviting me to take part in its discussion, and the other commentators who organized and took part in the workshop on Roads to Reference (July 16, 2020, via Zoom). This paper has been written thanks to the CONICET and two grants provided by the University of Buenos Aires (UBACyT 20020170100649BA, Res. 1041/2018) and ANPCyT (PICT 2016-0438).

\section{REFERENCES}

Devitt, Michael (2015). "Should Proper Names Still Seem So Problematic?", in A. Bianchi (ed.) On Reference. Oxford: Oxford University Press: 109-43.

Devitt, M. \& Kim Sterelny (1987). Language and Reality. Oxford: Blackwell.

Dickie, Imogen (2011). "How Proper Names Refer", Proceedings of the Aristotelian Society 111: 43-78.

Gómez Torrente, Mario (2019). Roads to Reference. Oxford: Oxford University Press.

Kaplan, David (1989). "Afterthoughts", in Joseph Almog, John Perry \& Howard Wettstein (eds.) Themes from Kaplan. Oxford: Oxford University Press: 565-614. 
Kripke, Saul (1980). Naming and Necessity. Cambridge: Harvard University Press.

Spohn, Wolfang (2002). "Laws, Ceteris Paribus

Conditions, and the Dynamics of Belief", Erkenntnis 57: 373-394.

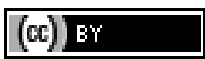

Manuscrito - Rev. Int. Fil. Campinas, v. 43, n. 4, pp. 22-34, Oct.-Dec. 2020. 